www.jmscr.igmpublication.org

Impact Factor (SJIF): 6.379

Index Copernicus Value: 79.54

ISSN (e)-2347-176x ISSN (p) 2455-0450

crossrefDOI: https://dx.doi.org/10.18535/jmscr/v6i12.123

Journal Of Medical Science And Clinical Research

IGM Publication

An Official Publication of IGM Publication

\title{
Sociodemographic correlates, stressful life events and hopelessness among impulsive suicide attempters- A hospital based study from North Kerala
}

\author{
Authors \\ Varada Panikkath $^{1}$, Yesudas K F ${ }^{2}$, Sumesh Balachandran ${ }^{3}$ \\ ${ }^{1}$ Junior Resident, Department of Psychiatry, Academy of Medical Sciences, Pariyaram, Kerala \\ ${ }^{2}$ Professor and HOD, Department of Psychiatry, Academy of Medical Sciences, Pariyaram, Kerala \\ Email:dr.yesudaskf@gmail.com \\ ${ }^{3}$ Assistant Professor, Department of Psychiatry, Academy of Medical Sciences, Pariyaram, Kerala \\ Email: sumesh.balachandran@gmail.com \\ *Corresponding Author \\ Dr Varada Panikkath
}

Junior Resident, Department of Psychiatry, ACME, Pariyaram, Kannur, Kerala, 670502, India

Email: varadapanikkath@gmail.com

\begin{abstract}
Suicide is a global phenomenon which is a silent epidemic. Suicide attempts have far-fetched effects of community and public health. Impulsive or unplanned suicide attempts constitute a major part of the suicide attempts. A hospital based cross sectional study was carried out to assess the sociodemographic profile, level of hopelessness, level of suicide intent and stressful life events in impulsive suicide attempters and to assess the correlation of hopelessness, suicidal intent and stressful life event among them. Those admitted in a tertiary care center with any mode of suicide attempt were included in the study. A total of 150 patients were included after meeting inclusion criteria. Beck's Hopelessness Scale and Beck's Suicide Intent Scale were administered to assess hopelessness and suicide intent. Presumptive Stressful Life Events Scale was used to assess life events. Based on the score of 4 items in suicide intent scale, impulsivity score was calculated and those who scored $<6$ were considered as impulsive attempters. Statistical analysis was carried out using SPSS version 24. $61.3 \%(N=92)$ of the sample were impulsive attempters. Among them $63 \%$ were females $(N=58)$ and $37 \%$ males $(N=34)$. Most common psychiatric diagnosis was adjustment disorder (27.2\%) followed by personality disorder (22.9\%) and alcohol dependence syndrome (17.4\%). Suicide intent was positively correlated with hopelessness, stressful life events score and number of stressful life events. A negative correlation was obtained for desirable life event score and suicide intent. The correlation of suicide intent score with undesirable life events was weak. Impulsive suicide attempts need more careful assessment and evaluation to prevent further suicide attempts and completed suicides. Accurate evaluation and management of impulsive trait or state may help in this.

Keywords: impulsive suicide attempts, hopelessness, suicide intent, stressful life events.
\end{abstract}

\section{Introduction}

Suicide is a global phenomenon which has enormous implications in public health. The
World Health Organization (WHO) defines suicide act as the injury with varying degrees of lethal intent and that suicide may be defined as a 
suicidal act with fatal outcome. ${ }^{(1)}$ According to WHO, every year, close to $8,00,000$ people die due to suicide that is one person every 40 seconds. Studies have shown that the suicide rates in India are comparable to that of USA and Australia. ${ }^{(2)}$ As per the National Crime Records Bureau report of 2015, the number of suicides in India has shown a $17.3 \%$ increase in the last decade (2005-2015). As per the latest data, prevalence of suicide in India is $10.6 \%$.In Kerala, rate of suicide is almost double of the national rate i.e., $21.6 \%$ which brings Kerala into the top 10 states with high rate of suicide. ${ }^{(3)}$

Deliberate self-harm or attempted suicide is defined as an act with non-fatal outcome, in which an individual deliberately initiates a non-habitual behavior that, without intervention from others, will cause self-harm, or deliberately ingests a substance in excess of the prescribed or generally recognized therapeutic dosage, and which is aimed at realizing changes which the subject desired via the actual or expected physical consequences. $^{(4)}$

Hopelessness is considered as one of the cardinal predictors of suicidal risk. Hopelessness is defined as a state of negative expectations and is an important correlate of suicide intent (Beck A T et al). ${ }^{(5)}$ Various studies identified hopelessness as an important indicator of suicide intent more than depression per se (Chandrasekaran \& Gnanaselane, 2005; Haw, Hawton, Houston, \& Townsend, 2003). ${ }^{(6),(7)}$ Suicidal intent is defined as the subjective expectation and desire for a selfdestructive act to end in death. The level of suicidal intent at the time of performing suicidal act is found as a prognosticator of future suicide intent. (Harris, Hawton and Zahl 2005; Suominen et al 2004). ${ }^{(8),(9)}$

Recent life changes are commonly associated with attempted suicide especially interpersonal stress. They can be acute problems such as having a serious argument with spouse, presence of a new member in the family, serious illness in self or a family member etc. They can have chronic life stressors also like marital discord, financial stressors, and academic difficulties etc. ${ }^{(10),(11)}$. Studies have identified that most of the suicide attempts in Asian countries are impulsive or unplanned. ${ }^{(2)}$ Impulsive attempters are found to be less depressed, to have lower expectation of lethality and to be less hopeless. ${ }^{(12)}$ Most of these studies regarding impulsive suicide attempts were conducted on western population.

Suicide is a major preventable cause of death worldwide. The first ever mental health action plan by WHO which was created in May 2013 has suicide prevention as an integral part of the plan. The aim is to reduce the rate of suicides worldwide by $10 \%$ by $2020{ }^{(1)}$ A previous suicide attempt is considered as an important risk factor for further suicide attempts (Diekstra, 1996,V Menon 2013). ${ }^{(13),(14)}$ So early identification of the cause for suicide attempts and level of suicidal intent play an important role in successful creation of suicide prevention strategies. Indian research regarding characteristics of unplanned suicides appear to be meager. Since most of the suicide attempters belong to younger age group and their attempts are mostly unplanned their characteristics and what prompt them or attempts need to be studied.

\section{Aims \& Objectives}

1. To study the prevalence of impulsive suicide attempts in a tertiary care center and to study socio-demographic profile of such patients

2. To investigate the stressful life events, level of hopelessness and the suicide intent in impulsive suicide attempters

3. To assess the correlation of stressful life events and level of hopelessness with suicidal intent in impulsive suicide attempters

\section{Materials \& Methods}

This is a hospital based cross sectional study. Participants were recruited by purposive sampling for a period of 1 year. A total of 150 patients were recruited in the present study and who were 
patients of either gender aged between 16-80 and were admitted in various intensive care units and wards of a tertiary care center following a suicide attempt. Detailed interview of the participant and reliable informant was carried out by the principal investigator after obtaining written informed consent. Denial of consent, unstable medical condition and lack of reliable informant were the exclusion criteria. Patients were categorized into impulsive attempters and planned attempters based on impulsivity score. This score was calculated based on the scores of question numbers 5, 6, 7 and 15 of Beck's Suicide Intent Scale (SIS). Those who scored less than 6 out of total 12 were classified as impulsive attempters and were further assessed. Level of hopelessness was assessed using Beck's Hopelessness Scale (BHS), suicidal intent was assessed using SIS, and stressful life events were assessed using Presumptive Stressful Life Events Scale (PSLES). Data obtained were analyzed using SPSS 24. Descriptive statistics was used to assess mean, standard deviation and interquartile range. Correlation between hopelessness, suicidal intent and stressful life events was assessed using Spearman's Rank Correlation Coefficient. P value $<0.05$ was considered as statistically significant.

\section{Results}

Study sample consisted of 150 suicide attempters with age varying from 16-80. Among the 150, $61.3 \%(\mathrm{~N}=92)$ scored impulsivity score of less than 6 and were categorized as impulsive attempters. These 92 were further evaluated using various scales.

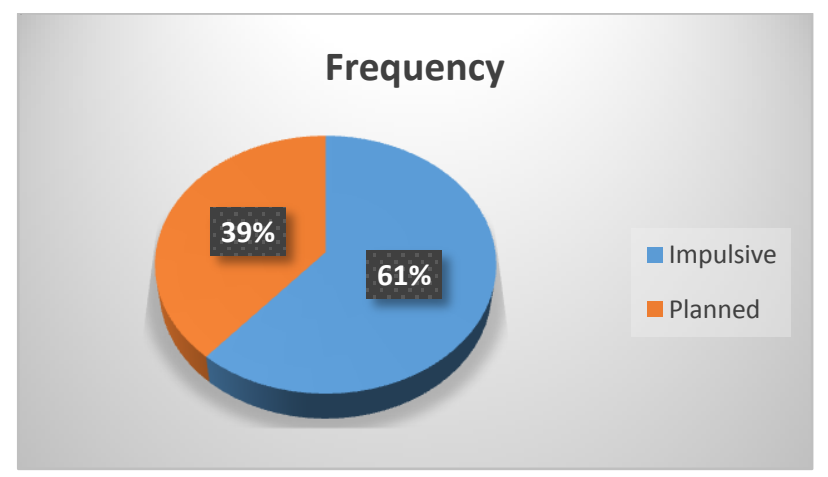

Figure 1: Frequency of impulsive and planned attempters
Among the impulsive attempters, 63\% (N=58) were females and $56.5 \%(\mathrm{~N}=52)$ were less than 30 years of age. Sociodemographic characteristics of impulsive attempters are given in the Table 1

Table 1: Sociodemographic characteristics of impulsive attempters

\begin{tabular}{|l|c|c|}
\hline Variable & Frequency & Percentage \\
\hline Gender & 34 & 37 \\
\hline Male & 58 & 63 \\
\hline Female & & \\
\hline Age group & 52 & 56.5 \\
\hline $16-29$ & 19 & 20.7 \\
\hline $30-39$ & 11 & 12 \\
\hline $40-49$ & 10 & 10.8 \\
\hline $50-75$ & & \\
\hline Occupation & 54 & 58.7 \\
\hline Unemployed & 38 & 41.3 \\
\hline Employed & & \\
\hline Marital status & 50 & 54.3 \\
\hline Married & 42 & 45.7 \\
\hline Unmarried & & \\
\hline Religion & 20 & 21.7 \\
\hline Christian & 65 & 71.7 \\
\hline Hindu & 7 & 7.6 \\
\hline Muslim & & \\
\hline Family type & 74 & 84.8 \\
\hline Nuclear & 18 & 15.2 \\
\hline Joint & 35 & 38 \\
\hline Background & 57 & 62 \\
\hline Rural & & \\
\hline Semi urban & & \\
\hline
\end{tabular}

Among the impulsive attempters, physical illness was present in $22.8 \%(\mathrm{~N}=21)$. There was past history of suicide attempt in $39.1 \%(\mathrm{~N}=36)$ and family history of suicide attempt was present in $16.3 \%(\mathrm{~N}=15)$. There was history of substance use in $34.8 \%(\mathrm{~N}=32)$. Poisoning and drug over dosage were the most common methods of attempt, $37 \%$ each $(\mathrm{N}=34)$. Hanging $(13 \%, \mathrm{~N}=12)$,jumping into well $(5.4 \%, \mathrm{~N}=5)$, cut injury $(5.4 \%, \mathrm{~N}=5)$ and burns $(2.2 \%, \mathrm{~N}=2)$ were the other methods of suicide attempt.

$27.2 \%(\mathrm{~N}=25)$ were diagnosed with adjustment disorder which was the most common diagnosis among the study population. $22.9 \%(\mathrm{~N}=21)$ were diagnosed with personality disorder and $17.4 \%$ $(\mathrm{N}=16)$ with alcohol dependence syndrome. 


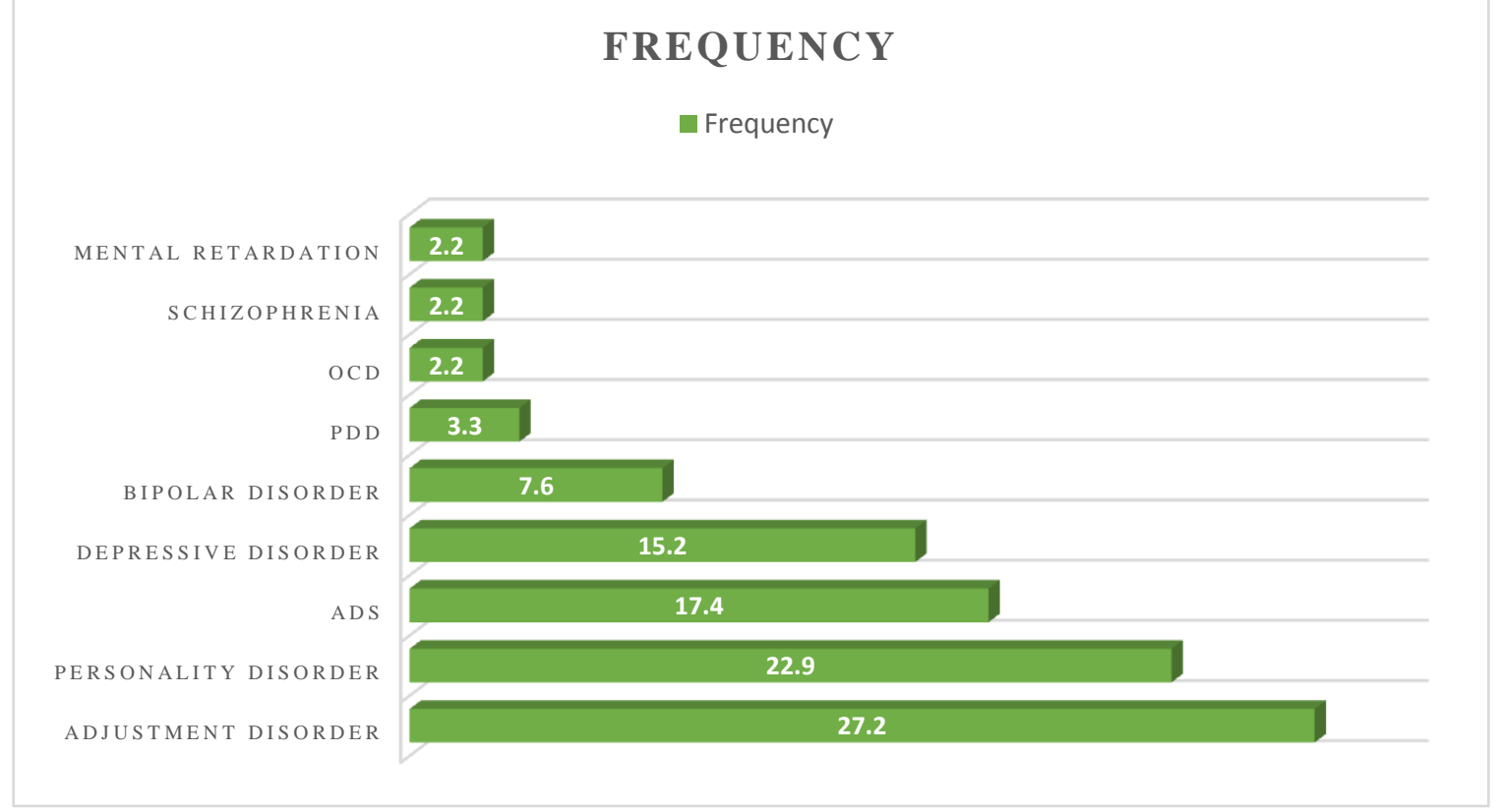

Figure 2: Frequency of psychiatric illnesses among impulsive attempters

$71.7 \%(\mathrm{~N}=66)$ of the study population reported moderate level of hopelessness. Mild and severe level of hopelessness were reported in $14.1 \%$ each $(\mathrm{N}=13)$.Suicide intent score was high among $59.8 \%(\mathrm{~N}=55)$. Medium suicide intent was reported by $38 \%(\mathrm{~N}=35)$ and low suicide intent by $2 \%(\mathrm{~N}=2.2)$.

Undesirable life events were reported by all the persons in the study population. Common among them were interpersonal conflicts like marital discord and family conflict. Desirable life events were reported by $72 \%(\mathrm{~N}=57)$ and ambiguous life events by $81.5 \%(\mathrm{~N}=75)$. Number of stressful life events varied from 3-14.

Correlation of suicide intent with desirable life events, undesirable life events, ambiguous life events and hopelessness was assessed using Spearman's rank correlation coefficient. Results showed that there was no correlation between ambiguous life events and suicide intent. However, there was correlation of suicide intent with hopelessness and desirable life events score. Correlation between hopelessness and suicide intent was obtained as $0.381(\mathrm{P}=0.000)$ which implies that there is a significant positive moderate to strong correlation of hopelessness and suicide intent. Also correlation between desirable life events and suicide intent was $-0.130(\mathrm{P}>0.05)$, which indicates that there is a moderate negative correlation between the two variables, even though statistical significance could not be obtained.

Correlation between undesirable life event score and suicide intent was 0.037 which was a weak positive correlation which was statistically in significant. With total life events score, correlation coefficient was $0.159(\mathrm{P}=0.130)$ which is a moderate positive correlation even though statistical significance could not be obtained. Number of stressful life events varied from 3-14 in the study population. When number of stressful life events were correlated with suicide intent score, we could obtain a strong positive correlation $(\mathrm{r}=0.176, \mathrm{P}=0.094)$, which indicates that as the number of stressful life events increased, suicide intent also increased. Spearman's Rank correlation coefficient of various variables are given in Table2.

Table 2: Correlation of suicide intent with hopelessness and stressful life event score

\begin{tabular}{|l|c|c|}
\hline Variable & $\begin{array}{c}\text { Spearman's } \\
\text { correlation coefficient }\end{array}$ & P value \\
\hline Hopelessness & 0.381 & 0.000 \\
\hline Undesirable life events score & 0.037 & 0.728 \\
\hline Desirable life events score & -0.130 & 0.215 \\
\hline $\begin{array}{l}\text { Total stressful life events } \\
\text { score life }\end{array}$ & 0.159 & 0.130 \\
\hline $\begin{array}{l}\text { Number of stressful } \\
\text { events }\end{array}$ & 0.176 & 0.094 \\
\hline
\end{tabular}




\section{Discussion}

This study included 150 suicide attempters who belonged to the age group of 16-80. Among them 92 were categorized as impulsive suicide attempters and their data was used for further analysis.

It is observed from the present study that impulsive suicide attempts were more among the females in this study.63\% of the impulsive attempters were females. Also majority belonged to younger age group i.e., $56.5 \%$ in $16-29$ age group. Studies conducted by Wei et al (2013) and Bagge et al (2013) corroborated these findings. (15),(16) Simon et al (2001), however, have reported more number of male attempters as impulsive in their study. An Indian study conducted by Kattimani et al (2015) also had reported male preponderance among impulsive attempters. ${ }^{(17)}$

Adjustment disorder was the most common diagnosis among the impulsive attempters followed by personality disorder. Emotionally unstable personality disorder and mixed personality disorders were diagnosed among the impulsive attempters. Impulsive and aggressive personality disorders are identified as risk factors for suicide attempts and completed suicides in previous studies (Dumais et al). ${ }^{(18)}$ Another common diagnosis is alcohol dependence syndrome which is also a known risk factor for increasing impulsivity. Authors have reported less prevalence of depression among impulsive attempters which was corroborated in the present study. ${ }^{(19)}$

Level of hopelessness was moderate to severe among impulsive suicide attempters. Hopelessness is a dynamic concept and previous studies have reported conflicting evidences regarding association of hopelessness with suicide intent. ${ }^{(20)}$ We found a strong positive correlation between hopelessness and suicide intent among impulsive suicide attempters.

All the impulsive suicide attempters had reported undesirable life events. Interpersonal conflicts were the most common like marital conflict or family conflict. Failure in exams or interview and love failure were also commonly reported by impulsive attempters. On the other hand loss of a spouse or family member and similar stressors were less common among impulsive attempters. There was no strong correlation between the mean stress score of undesirable events and suicide intent. However, there was a negative correlation between desirable life events score and suicide intent which suggests that desirable life events could act as a protective factor for suicide attempts.

\section{Limitations}

This is a hospital based cross sectional study with a small sample size. So generalization of the results is questionable. Whether impulsivity is a personality trait or a state was not assessed in this study which has an important role in determining further course of action. Also coping strategies and resilience of persons may affect the response to stress and decision making which was not assessed in this study. Proximity of the stressful event may make the event a triggering factor for suicide event. This was not analyzed in the present study.

To conclude impulsive suicide attempters are common among the suicide attempters who seek medical treatment. Many of them are having psychiatric illnesses which affect their decision making, stress tolerance and coping skills which is a risk factor for multiple suicide attempts. Proper identification and treatment of such conditions like personality disorder and substance use are of primary importance in suicide prevention. Furthermore impulsivity could be part of personality trait or a state. This also needs to be assessed. Interpersonal stress, especially marriage related conflicts were more frequent in the study population. Various studies have suggested that non-fatal suicide attempts in context of acute interpersonal stress shows the coping skills and stress tolerance among the individuals. Community programs to enhance the coping skills, communication skills etc. may help in preventing suicide attempts. 
High positive correlation of hopelessness, life events and suicide intent shows the need of accurate assessment of these factors prior to deciding the management. High intent attempters may benefit from an eclectic approach and detailed psychiatric evaluation during inpatient treatment, followed by frequent reviews and continuous community surveillance. Need of preparing a suicide prevention program and sensitization of primary care personnel (including "gatekeepers") regarding the situation is the need of the hour.

\section{References}

1. World Health Organization. Preventing suicide. 2014;143(7):609-10.

2. Radhakrishnan R, Andrade C. Suicide: an Indian perspective. Indian journal of psychiatry. 2012 Oct;54(4):304.

3. Mid-year E. Chapter - 2 Suicides in India. 2010;(169):169-89.

4. Platt S, Kerkhof A, Schmidtke A, Bjerke T, Crepet P, Querejeta I, et al. Parasuicide in Europe: the WHOIEURO multicentre study on parasuicide . I . Introduction and preliminary analysis for. 1992;97-104.

5. Beck AT, Kovacs M, Weissman A. Hopelessness and Suicidal Behavior: An Overview. JAMA J Am Med Assoc. 1975;234(11):1146-9.

6. Chandrasekaran R, Gnanaseelan J, Sahai A, Swaminathan RP, Perme B. Psychiatric and personality disorders in survivors following their first suicide attempt. Indian journal of psychiatry. $2003 \mathrm{Apr} ; 45(2): 45$.

7. Haw C, Hawton K, Houston K, Townsend E. Psychiatric and personality disorders in deliberate self-harm patients. $\mathrm{Br}$ J Psychiatry. 2001;178(JAN.):48-54.

8. Harriss L, Hawton K. Suicidal intent in deliberate self-harm and the risk of suicide: The predictive power of the Suicide Intent Scale. J Affect Disord. 2005;86(2-3):225-33.

9. Suominen K, Isometsä E, Ostamo A,
Lönnqvist J. NoLevel of suicidal intent predicts overall mortality and suicide after attempted suicide: a 12-year follow-up study. BMC Psychiatry [Internet]. 2004;4(1):11. Available from: http://www.biomedcentral.com/1471244X/4/11

10. Latha KS, Bhat SM, D'Souza P. Suicide attempters in a general hospital unit in India: Their socio-demographic and clinical profile - Emphasis on crosscultural aspects. Acta Psychiatr Scand. 1996;94(1):26-30.

11. Kumar CTS, Mohan R, Ranjith G, Chandrasekaran R. Characteristics of high intent suicide attempters admitted to a general hospital. J Affect Disord. 2006;91(1):77-81.

12. Spokas M, Wenzel A, Brown GK, Beck AT. Characteristics of individuals who make impulsive suicide attempts. J Affect Disord. 2012;136(3):1121-5.

13. Diekstra RFW. The epidemiology of suicide and parasuicide. Arch Suicide Res. 1996;2(1):1-29.

14. Menon V, Kattimani S, Shrivastava MK, Thazath HK. Clinical and sociodemographic correlates of suicidal intent among young adults: a study from South India. Crisis [Internet]. 2013 Jan 1 [cited 2016 Sep 27];34(4):282-8. Available from:

http://www.ncbi.nlm.nih.gov/pubmed/236 85339

15. Wei S, Liu L, Bi B, Li H, Hou J, Chen W, et al. Comparison of impulsive and nonimpulsive suicide attempt patients treated in the emergency departments of four general hospitals in Shenyang, China. Gen Hosp Psychiatry. 2013;35(2):186-91.

16. Bagge CL, Littlefield AK, Lee HJ. Correlates of proximal premeditation among recently hospitalized suicide attempters. J Affect Disord. 2013;150(2):559-64. 
17. Kattimani S, Sarkar S, Rajkumar R, Menon V. Stressful life events, hopelessness, and coping strategies among impulsive suicide attempters. J Neurosci Rural Pract [Internet]. 2015;6(2):171. Available from: http://www.ruralneuropractice.com/text.as p?2015/6/2/171/153222

18. Dumais A, Lesage AD, Alda M, Rouleau G, Dumont M, Chawky N, et al. Risk Factors for Suicide Completion in Major Depression: A ... Am J Psychiatry. 2005;162(11):2116-9.

19. Rimkeviciene J, Ogorman J, De Leo D. Impulsive suicide attempts: A systematic literature review of definitions, characteristics and risk factors. Vol. 171, Journal of Affective Disorders. 2015. p. 93-104.

20. Conner KR, Phillips MR, Meldrum S, Knox KL, Zhang Y, Yang G. Low-planned suicides in China. Psychol Med. 2005;35(8):1197-204. 